\title{
COMPARISON OF OUTCOMES OF DESARDA VERSUS LICHTENSTEIN REPAIR FOR INGUINAL HERNIA IN TERMS OF OPERATIVE TIME, POSTOPERATIVE PAIN AND RETURN TO NORMAL ACTIVITY.
}

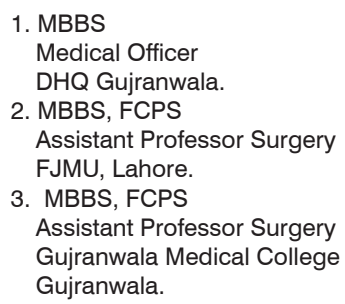

Correspondence Address: Dr. Mudassar Murtaza Assistant Professor Surgery FJMU, Lahore.

339 E Block Johar Town Lahore. drmudassirmurtaza@gmail.com

Article received on:

02/03/2019

Accepted for publication: 21/10/2019

\begin{abstract}
Syeda Hussane Zahra', Mudassar Murtaza ${ }^{2}$, Muhammad Ansar Aslam ${ }^{3}$
ABSTRACT... Objectives: Our aim was to compare the outcome of Desarda repair versus Lichtenstein repair. Study Design: Randomized Controlled trial. Settings: DHQ Hospital Gujranwala. Period: From 27 October 2017 to 27 March 2018. Material \& Methods: We included 60 patients in the study. In 30 patients Lichtenstein Hernia Repair was done and in 30 patients Desarda repair was done. The demographic information, outcome in the form of duration of operation, postoperative pain, and return to normal activity was recorded. All this information was collected through a predesigned performa. Patients were followed up on OPD basis. Data analysis was done by using SPSS 20. Results: Mean operative time in group $A$ and group $B$ was $61.20 \pm 12.558$ and $71.89 \pm 13.118$ respectively. Statistically significant difference was present in treatment group in term of operative time i.e. (P-value $=<.05$ ). In both treatment group, mean time to require to start normal activity in $D$ and $L$ was $10.06 \pm 1.771$ and $11.14 \pm 2.485$ and it is statistically significant $(P$-value $=.001)$. Postoperative pain was less but statistically insignificant in study group. Conclusion: Desarda repair is better than Lichtenstein repair in terms of operative time and return to normal activity.
\end{abstract}

Key words: Desarda Repair, Inguinal Hernia, Lichtenstein, Postoperative Pain, Seroma.

Article Citation: Zahra SH, Murtaza M, Aslam MA. Comparison of outcomes of Desarda versus Lichtenstein repair for inguinal hernia in terms of operative time, postoperative pain and return to normal activity. Professional Med J 2020; 27(7):1465-1469. DOI: 10.29309/TPMJ/2020.27.07.4298

\section{INTRODUCTION}

Inguinal hernia is a common surgical outdoor problem. In emergency situation patients with inguinal hernia come with complications like strangulation and obstruction which require immediate surgery. The incidence of inguinal hernia increases in proportion to increasing age. A population based study in Olmsted County (Minnesota) has shown incidence of 368 and 44 per 100,000 among male and female gender respectively. ${ }^{1}$

In one district of Punjab the prevalence of inguinal hernia was $70 \%$ among all hernias. It is more prevalent in male gender. Numerous factors contribute to the etiology of inguinal hernia. Most commonly described factors are progressive weakness of abdominal wall muscles, constipation, urinary flow obstruction, smoking, collagen disorders, genetic predisposition, obesity, pregnancy and chronic cough. ${ }^{2}$
The most appropriate treatment of inguinal hernia is to repair surgically. Surgical repair not only relieves symptoms but also prevents major complications. Worldwide more than 50 different techniques have been employed due to some but different problems with all techniques. Commonly used techniques are basically of two types. One is based on tissue repair and other uses the mesh. These include Shouldice, Lichtenstein, Darning repair, Totally Extra-Peritoneal (TEP) and Trans Abdominal Pre-Peritoneal (TAPP)

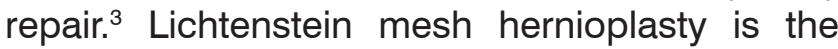
most commonly performed procedure in all over the world due to very low recurrence. The main reason behind is tension free repair. However it is expensive and not as commonly used in underdeveloped and developing countries as in developed countries. Complications of mesh hernioplasty are also well known. Some of these include chronic pain, infection, Seroma formation, foreign body sensation and mesh migration. Most 
of the surgeons still refrain from using mesh in emergency settings.

Due to these problems surgeons are still working on evolving new flawless techniques. Desarda's technique is one of these techniques. He claims no recurrence even in recurrent hernias. Some centers reported recurrence but later on found due to faulty technique by those surgeons.

In this technique a 1.5 to $2 \mathrm{~cm}$ width segment of external oblique aponeurosis is brought behind the cord .lower end is sutured to inguinal ligament while upper end of leaf is sutured to internal oblique muscle. It is physiologically dynamic segment and hence tension free. ${ }^{4}$

Various studies have been conducted all over the world. Manyilirah et.al proved that Desarda takes shorter operative time than Lichtenstein and it is statistically significant. ${ }^{5}$ Rodriguez et al. proved that difference in operative time in both techniques was also statistically significant. Early return to normal activity was seen in Desarda. ${ }^{6}$ Szopinski et al. found that frequency of seroma formation was less in Desarda as compared to Lichtenstein in 30 days. $^{7}$ Youssef $\mathrm{T}$ et al found it to be cost effective. ${ }^{8}$ Recently a systematic review of articles published between 2001 and July 2017 by $\mathrm{Ge} \mathrm{H}$, et al concluded that there is no difference between two techniques in short term effectiveness. ${ }^{9}$ However a few studies have been conducted in Pakistan. If more studies are conducted and show the effectiveness of Desarda's technique in relation to its outcomes then it would be highly economical procedure in already resource confined country like Pakistan.

\section{MATERIAL \& METHODS}

It was a randomized controlled trial conducted at DHQ hospital, Gujranwala for 6 months from October 2017 to March 2018. Taking mean VAS pain score 2.86 with 0.70 standard deviation in Desarda group and 3.50 with standard deviation of 0.97 in Lichtenstein group with $80 \%$ power of study and $95 \%$ significance level 60 patients were included. Sixty patients were randomized by lottery method into two equal groups comprising 30 patients in each group. Group
D consisting patients who underwent Desarda repair and group $\mathrm{L}$ comprising patients who underwent Lichtenstein repair. All male patients with primary unilateral hernia aged more than 25 years were included. Patients with bilateral or complicated hernia were excluded. We made hypothesis that there is significant difference in operative time, post-operative pain score, and return to normal activity in patients undergoing Desarda vs. Lichtenstein repair. After approval from hospital ethical committee, patients meeting the inclusion criteria were admitted through out-patient department in Surgical Ward 7 of DHQ Hospital, Gujranwala. An informed written consent was taken. Demographic profiles were recorded. Prophylactic antibiotic (CEFTRIAXONE $1 \mathrm{G} \mathrm{I/V)} \mathrm{was} \mathrm{administered} \mathrm{before} \mathrm{skin} \mathrm{incision.}$ All patients were operated by consultant level surgeons. Mean operative time was recorded by paramedical staff starting from skin incision to skin stitches in minutes. Postoperative pain was measured using visual analogue scale ranging from 1 (no pain) to 10 (maximum pain) at day 1,2 and day 7 . Return to normal activity was defined as the patient's ability to perform elementary activities e.g. dressing, bathing and walking (basic activity), and returning to all previously performed activities i.e. office work (work activities). It was measured from the date of operation till the patient starts doing these activities. Seroma formation as secondary outcome was defined as collection of serous fluid after surgery noted on $1^{\text {st }}, 7$ th, 14 th and 30th postoperative day. Outcomes were recorded on predesigned performa. Data was subjected to analysis on SSPS version 20. Quantitative variables such as age, BMI, mean VAS, operation time, and return to normal activity were analyzed, calculating their mean and standard deviation. T test was applied for comparison of two groups. A $p$ value of less or equal to 0.05 was considered significant. Confounders like age, BMI were controlled through stratification. Post stratification T test was applied, considering $p$ value of 0.05 as significant.

\section{RESULTS}

In our study a sampled population of 60 patients with 30 in each group was included. Mean age, BMI and mean VAS score on day 1,2 and day 7 
are presented in Table-I.

\begin{tabular}{|l|c|c|c|}
\hline \multicolumn{1}{|c|}{ Variable } & $\begin{array}{c}\text { Group D } \\
\text { (Desarda) }\end{array}$ & $\begin{array}{c}\text { Group L } \\
\text { (Lichtenstein) }\end{array}$ & $\begin{array}{c}\text { P- } \\
\text { Value }\end{array}$ \\
\hline Age (years) & $41.30 \pm 17.04$ & $41.77 \pm 14.44$ & 0.91 \\
\hline Pain Score & & & \\
Day 1 & $5.0 \pm 1.89$ & $5.70 \pm 1.74$ & 0.14 \\
Day 2 & $2.83 \pm 1.08$ & $3.03 \pm 1.52$ & 0.56 \\
$7^{\text {th }}$ day & $2.12 \pm 2.31$ & $2.24 \pm 1.49$ & 1.27 \\
\hline BMl & $24.33 \pm 1.44$ & $23.17 \pm 4.46$ & 0.18 \\
\hline
\end{tabular}

Table-I. Comparison of age, BMI and VAS score in both groups.

Mean operative time in group $D$ and group $L$ was $61.20 \pm 12.558$ and $71.89 \pm 13.118$ respectively. Statistically significant difference was present in $\mathrm{D}$ group in term of operative time i.e. (P-value $=<$ .05). Mean operative time in posterior wall repair in group $D$ and group $L$ was $13.91 \pm 2.483$ and $17.84 \pm 3.023$ respectively which was statistically significant (P-value $=<.05)$. Mean time required to return to normal activity (in days) in group $D$ and $L$ was $10.06 \pm 1.771$ and $11.14 \pm 2.485$ respectively with a statistically significant $p$ value $(P-$ value $=$.001).Seroma formation in both treatment group was not statistically significant $(P-$ value $=.310)$. Majority comprising $72.4 \%$ patients in both treatment groups didn't develop seroma formation with $36.7 \%$ in group D and $29.14 \%$ in group L. $23 \%$ of patients in group $D(n=7)$ and $20 \%$ of patients in group $L(n=6)$ developed seroma formation on 1st day. On 7th day, 3\% developed seroma formation in group $D$ $(n=1)$ versus $13.3 \%$ of patients in group $L(n=4)$. No patient developed seroma in group $D$ but $13.3 \%$ of patients in group $L(n=4)$ developed seroma on 14th day. Seroma formation was same on 30 th day.

\section{DISCUSSION}

Most frequently performed procedure in surgical floor is inguinal hernia repair and Bassini described, for the first time, true inguinal hernia repair. There is continuing debate regarding the gold standard procedure for inguinal hernia repair. These days, Mesh repair (Lichtenstein repair) has gained universal acceptance because of its simplicity, better results and decrease in complication but use of mesh in young patient was always a hot debate and conflict for having no data about long term effect of mesh and for decreasing male sexual activity. This made surgeon to give preference to Desarda for not only in primary but also in strangulated hernia. ${ }^{10}$

Desarda repair is increasingly being used in developing and underdeveloped countries. Very few studies are reported in developed countries possibly due to financial burdens of prosthetic mesh. Most of the patients operated by Desarda repair are of low socioeconomic status. ${ }^{11}$

Rodriguez, et al proved in his study that Desarda takes more time than Lichtenstein (48 vs. $39 \mathrm{~min}$ ) and it was statistically significant $P<.05$. (6) This time is very less as compared to our study.

In another research by Gedam et al there was no significant difference in operative time and was approximately 73 minutes in both techniques. ${ }^{12}$ Comparing it to our study it is evident that it is significantly lower in Desarda repair in our study whereas it is almost equal in Lichtenstein repair.

In one Pakistani study by Ahmed $M$ et al at Muzaffargarh, it was $55.53 \pm 6.81 .{ }^{13}$ In our study, it is about 6 minutes more in Desarda repair.

Szopinski et al reported in his randomized controlled trial that return to normal activity was slightly more in D group. However the difference was not statistically significant. He followed his patients up to 36 months postoperatively regarding chronic pain. He used both VAS and Sheffield scale. In both early, which was measured after $7^{\text {th }}$ and $30^{\text {th }}$ postoperative day, and chronic, lasting >3 months, pain was not significantly different in both groups. ${ }^{7}$ In author's study data showed that desarda has significantly reduce time for postoperative normal activity resumption in comparison to Lichtenstein that is $(9.26 \pm 1.771$ vs. $11 \pm 2.485 \mathrm{P}$ value $=.001)$. Gedam et al conducted a cohort study on 187 cases. In this study, pain was assessed on day 1, 3, 7, 30 and 90 by using VAS. Pain was significantly less in first 7 postoperative days in Desarda group ( $p$ $=0.09$ ) as compared to Lichtenstein. Patients with Desarda repair becomes ambulatory earlier 
$(p=0.001) .{ }^{12}$ These results are similar to our study.

Hussain A, et al conducted a study comparing Darn Repair with Desarda repair in emergency cases. In this study mean operative time in Desarda repair was $55.53 \pm 6.81$ minutes, which is significantly low as compared to our study. This might be due to urgency in emergency cases as compared to elective surgery. ${ }^{14}$

\section{CONCLUSION}

Desarda repair is superior than Lichtenstein repair in terms of operative time and return to normal activity. However postoperative pain and seroma formation had no statistically significant difference in both treatment groups.

\section{Copyright@ 21 Oct, 2019.}

\section{REFERENCES}

1. Zendejas B, Ramirez T, Jones T, Kuchena A, Ali SM. Incidence of inguinal hernia repairs in Olmsted County, MN: A population-based study. Ann Surg 2013; 257(3): 520-526.

2. Iqbal MN, Akhter S, Irfan M. Prevalence of hernia in relation to various risk factors in Narowal, Pakistan. Science letters. 2015; 3(1):29-32.

3. Sgourakis G, Dedemadi G, Gockel I, Schmidtmann I, Lanitis S, et al. Laparoscopic totally extraperitoneal versus open preperitoneal mesh repair for inguinal hernia recurrence: A decision analysis based on net health benefits. Surg Endosc 2013; 27(7): 2526-41.

4. Desarda MP. Physiological repair of inguinal hernia: A new technique (study of $\mathbf{8 6 0}$ patients). Hernia 2005; 10:143-6.

5. Manyilirah W, Kijjambu S, Upoki A, Kiryabwire J. Comparison of non-mesh (Desarda) and mesh (Lichtenstein) methods for inguinal hernia repair among black African patients: A short-term doubleblind RCT. Hernia 2012; 16: 133-44.
6. Rodriguez PRI, Herrera PP, Gonzalez OL, Alonso JRC, Blanco HSR. A randomized trial comparing lichtenstein repair and no mesh desarda repair for inguinal hernia: A study of 1382 patients. East Cent Afr J Surg 2013; (18) 2: 18-25.

7. Szopinski J, Dabrowieki S, Pierscinski S, Jackowski M, Jaworski M, Szuflet Z. Desarda vs Lichtenstein for primary inguinal hernia treatment: 3-year results of a randomized clinical trial. World J Surg 2012; 36(6):984-92.

8. Youssef T, El-Alfy K, Farid M . Randomized clinical trial of desarda versus lichtenstein repair for treatment of primary inguinal hernia. Int J Surg 2015; 20: 28-34.

9. Ge H, Liang $\mathrm{C}, \mathrm{Xu} \mathrm{Y,} \mathrm{Ren} \mathrm{S,} \mathrm{Wu} \mathrm{J.} \mathrm{Desarda} \mathrm{versus}$ lichtenstein technique for the treatment of primary inguinal hernia: A systematic review. Int J Surg. 2018; 50:22-27.

10. Bashir S, Afzal MO, Rafi Y. Desarda technique for inguinal hernia repair, a multicenter experience. PJMHS 2015; 9;1;311-13

11. Roy BC, Hanifa A, Naher S, Baset A, Sarkar P, Outcome of desarda repair in inguinal hernia. A study in northern part of Bangladesh. International Journal of Medical Science and Public Health. 2016; 1; 5(3):521-5.

12. Gedam BS, Bansod PY, Kale VB, Shah Y, Akhtar m. A comparative study of Desarda's technique with Lichtenstein mesh repair in treatment of inguinal hernia: A prospective cohort study. Int J Surg 2017; 39:150-55.

13. Ahmed M, Manzoor F, Kausar R. Inguinal hernia: Clinical presentation and postoperative complications of patients when treated with Desarda technique. Ann. Pak. inst. Med. Sci. 2017; 13(1):3-6.

14. Hussain A, Mehsam S, Ali M, Rasul S, Parveen S, Memon A. Emergency inguinal hernia repair: Comparison of Desarda'=s vs. Darning technique. J Ayub Med Coll Abbottabad 2017; 29(4):551-3. 


\begin{tabular}{|c|c|c|}
\hline \multicolumn{3}{c}{ AUTHORSHIP AND CONTRIBUTION DECLARATION } \\
\hline Sr. \# & Author(s) Full Name & \multicolumn{1}{c|}{ Contribution to the paper } \\
\hline 1 & Syeda Hussane Zahra & Study design, Data collection. \\
\hline 2 & Mudassar Murtaza & $\begin{array}{l}\text { Article writing, Data analysis, } \\
\text { Discussion, Flnal technical, } \\
\text { Proof reading. } \\
\text { Introduction + computer work } \\
\text { + references, data collection. }\end{array}$ \\
\hline 3 & Muhammad Ansar Aslam \\
\hline
\end{tabular}

